\title{
On the Nature and Formation of the Fibrillar Nets Produced by Protoplasts of Saccharomyces cerevisiae in Liquid Media: An Electronmicroscopic, X-ray Diffraction and Chemical Study
}

\author{
By D. R. KREGER \\ Department of Plant Physiology, University of Groningen, The Netherlands \\ AND MARIE KOPECKÁ \\ Department of General Biology, Faculty of Medicine, \\ J. E. Purkyně University, Brno, Czechoslovakia
}

(Received 7 September 1973; revised 27 May 1975)

\begin{abstract}
SUMMARY
The nets produced by protoplasts of Saccharomyces cerevisiae in liquid culture media consisted of microfibrils about $20 \mathrm{~nm}$ wide, forming flat, fairly straight bundles of variable width and length, up to about $500 \mathrm{~nm}$ wide and $4 \mu \mathrm{m}$ long. Ends of microfibrils were seldom found. They were not attacked by chitinase or

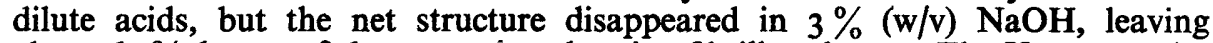
about $60 \%$ dry wt of the nets as partly microfibrillar clusters. The X-ray powder pattern from the nets, in contrast to that from normal walls, exhibited a set of well-defined rings which identified two micro-crystalline constituents: chitin and unbranched chains of $\beta$-(I $\rightarrow 3$ )-linked D-glucose residues. These latter were the alkali-soluble fraction. The X-ray diagram of the glucan, corresponding to that of paramylon, indicated an in vivo crystal modification. Up to $15 \%$ dry wt was chitin which was formed de novo by the protoplasts.

A fine net structure of microfibrils about $7 \cdot 5$ to $10 \mathrm{~nm}$ thick with meshes about 20 to $60 \mathrm{~nm}$ wide was demonstrated in normal walls, forming the entire inner layer and consisting mainly of yeast glucan. This glucan and chitin were only slightly crystalline in these walls. The features of the glucan and chitin of the protoplast nets indicate that enzymes active in normal wall formation were differentially removed or inactivated by the liquid medium.
\end{abstract}

\section{INTRODUCTION}

The protoplasts of Saccharomyces cerevisiae, cultivated in liquid media, do not build a new complete wall, only a network of microfibrils (Eddy \& Williamson, 1959; Nečas, 1961). In solid media, however, complete cell walls may be synthesized (Nečas, 1961). This difference has been attributed to partial removal by the liquid medium of the amorphous mannan fraction, its precursors or synthesizing enzymes (Nečas \& Svoboda, 1967).

Eddy \& Williamson (1959) found that the fibrillar nets contained glucose, mannose and about $27 \%(w / w)$ of glucosamine, suggesting a high chitin content. However, unlike chitin, the microfibrils are readily soluble in dilute alkali and are therefore probably largely glucan (Kopecká, Čtvrtníček \& Nečas, 1967). This was confirmed when glucose was found to be the only product of hydrolysis of purified nets (Svoboda \& Nečas, 1970).

This paper describes work to elucidate further the chemical nature of the nets. The problems investigated are: (i) whether the alkali-soluble glucan of the nets corresponds to the 
giucan known as hydroglucan, which is also alkali-soluble and microfibrillar, but is obtained in vitro from the glucan of the normal wall by partial hydrolysis and then is normally microcrystalline (Houwink \& Kreger, 1953); (ii) whether the nets contain chitin, as is suggested by the results mentioned above (Eddy \& Williamson, 1959) and also by those of Novaes-Ledieu \& Garcia-Mendoza (1970) for regenerated walls of Candida utilis (a chitin content of $18 \%$ dry wt was reported, whereas the normal walls, like those of $S$. cerevisiae, have less than $\mathrm{I} \%$ ); (iii) whether the glucan of the normal wall is amorphous (Bowden \& Hodgson, 1970; Bacon et al. 1970) or may be associated with a fine microfibrillar network observed in parts of such walls (Houwink \& Kreger, 1953; Streiblová, 1968).

Preliminary results have already been published (Kreger \& Kopecká, 1973).

\section{METHODS}

Protoplasts and fibrillar nets. Saccharomyces cerevisiae (strain $\mathrm{k} 7$ ) was centrifuged from a culture in exponential growth in malt extract $(\mathrm{pH} 5 \cdot 4)$, 10 to $15 \mathrm{~h}$ after inoculation. The yeast was washed with distilled water and transferred to McIlvaine citrate-phosphate buffer, pH 5.4, with $0.6 \mathrm{M}-\mathrm{KCl}, 0.0 \mathrm{I} \mathrm{M}-\mathrm{MgSO}_{4}$ and 20 to $30 \mathrm{mg}$ dry wt of fresh, freeze-dried snail gastric juice (Helix pomatia)/ml. After 3 to $6 \mathrm{~h}$ of incubation on a rotary shaker at $28{ }^{\circ} \mathrm{C}$ the percentage of released protoplasts was estimated visually. Only samples containing nothing but protoplasts and remnants of walls were used for experiments.

The protoplasts were separated from the remnants of cell walls by several 6 min centrifugations at $300 \mathrm{~g}$ in a solution of the same composition but without snail enzyme. Most of the protoplasts were in the pellet, whereas the cell wall remnants remained mainly in the supernatant and were isolated and collected as described below for the nets. After six successive similar washings the protoplasts were inoculated into either $\mathrm{NI}$ medium (5 g glucose, $\mathrm{I} \cdot 25 \mathrm{~g}$ asparagine, $\mathrm{I} \cdot 25 \mathrm{~g} \mathrm{KH}_{2} \mathrm{PO}_{4}, 0.425 \mathrm{~g} \mathrm{MgSO}_{4}, 50 \mathrm{ml}$ distilled water, $\mathrm{pH} 5.4$; Nečas, I965), or into a solution of $0.4 \mathrm{M} \mathrm{D}$-glucose and $0.3 \mathrm{M}-\mathrm{KCl}$ in McIlvaine citratephosphate buffer $\mathrm{pH} 5.4$, and incubated on a rotary shaker at $28^{\circ} \mathrm{C}$ for $24 \mathrm{~h}$.

The protoplasts were then centrifuged, lysed with distilled water and, in order to remove proteins, the fibrillar nets were digested in a $1 \%(w / v)$ solution of trypsin (Spofa) in phosphate buffer $\mathrm{pH} 7.2$ at $37^{\circ} \mathrm{C}$ for $12 \mathrm{~h}$. After another washing with distilled water, lipids were extracted with $96 \%$ ethanol and the last remnants of cytoplasmic material were removed by shaking with hot water. The nets were dried on a sterile Petri dish at $45^{\circ} \mathrm{C}$. Electron microscopy showed that contamination by undigested old walls was no more than one to every 100 nets, and no bud scars were observed. Three such samples were prepared for different yeast cultures, designated samples $I, 2$ and 3 .

Isolation of partly digested walls from protoplast samples. Yeast cells from the exponential growth phase were washed with distilled water and incubated with snail gastric juice as indicated above. The fresh protoplasts were lysed with distilled water, and the remaining cell walls were collected and purified as described for purification of the nets.

Preparation of ' $\mathrm{HCl}$ walls'. Cell wall remnants isolated as described above were heated with $2 \%(\mathrm{w} / \mathrm{v}) \mathrm{HCl}$ for $3 \mathrm{~h}$ in a boiling water bath, purified with trypsin and ethanol, washed with distilled water and dried. $\mathrm{HCl}$ walls were also prepared by a similar $\mathrm{HCl}$ treatment of walls of baker's yeast, obtained by shaking the yeast with glass beads.

Extractions. Removal of chitin was done by treatment either with $30 \%$ (w/v) $\mathrm{HCl}$ at $3{ }^{\circ} \mathrm{C}$ for $2.5 \mathrm{~h}$, or with fungal chitinase (Koch-Light) at a concentration of $1.5 \mathrm{mg} \mathrm{dry} \mathrm{wt} / \mathrm{ml}$ in phosphate buffer $\mathrm{pH} 6.5$ at $37^{\circ} \mathrm{C}$ for $\mathrm{Io} \mathrm{h}$, with penicillin and streptomycin (Spofa) added to prevent bacterial contamination. The nets were then washed five times with 
distilled water. For isolation of chitin, about $\mathrm{I} \cdot 5 \mathrm{mg}$ of nets were placed in $30 \%(\mathrm{w} / \mathrm{v}) \mathrm{HCl}$ ( $\mathrm{I} \mathrm{ml}$ ) as indicated above. Chitin was precipitated after tenfold dilution with distilled water by adding 5 drops of $10 \%(\mathrm{w} / \mathrm{v}) \mathrm{NaOH}$. The white precipitate was centrifuged, washed and dried. Treatment with $3 \%(\mathrm{w} / \mathrm{v}) \mathrm{NaOH}$ was either at $4{ }^{\circ} \mathrm{C}$ for 3 to 9 days, or in a boiling water bath for $3 \mathrm{~h}$. Alkali-insoluble fractions were obtained from both samples, but only the supernatant from the extraction at $4{ }^{\circ} \mathrm{C}$ yielded a precipitate by adjusting to $\mathrm{pH} 5$ with acetic acid. Treatment with $2 \% \mathrm{HCl}$ was in a boiling water bath for $3 \mathrm{~h}$, using about I00 ml of $2 \%$ (w/v) HCl/mg nets. Treatment with $0.5 \mathrm{M}$-acetic acid was at $90{ }^{\circ} \mathrm{C}$ for $95 \mathrm{~h}$ (Manners \& Masson, 1969) and the acid was changed at 3 to $12 \mathrm{~h}$ intervals.

Protoplast pretreatment with chitinase. Protoplasts were prepared as described above except that the snail enzyme treatment was prolonged to $8 \mathrm{~h}$ and there were only two washings with the enzyme-free medium. The protoplasts were then incubated with chitinase (Io $\mathrm{mg}$ dry wt of chitinase $/ 20 \mathrm{ml}$ of phosphate buffer $\mathrm{pH} 6.2$ with $0.6 \mathrm{M}-\mathrm{KCl}$ ) for $16 \mathrm{~h}$ at $28^{\circ} \mathrm{C}$ on a rotary shaker, centrifuged, incubated for a further $2 \mathrm{~h}$ in snail enzyme solution and subsequently washed four times with $\mathrm{I} \mathrm{M}-\mathrm{KCl}$ in buffer $(\mathrm{pH} 5 \cdot 5)$. Cultivation followed for $24 \mathrm{~h}$ in nutrient medium, with lysis and cleaning as described above, except that after extraction with ethanol the protoplasts were treated with pancreatic ribonuclease because of the presence of a large amount of cytoplasmic material; this could not be fully removed. No fragments of old walls or any skeletons of bud scars could be found on electronmicroscopic inspection of fields containing several hundred nets.

Anthrone method. The residual sedimented material of fibrillar nets (Table I) was suspended in $\mathrm{I} \mathrm{ml}$ of $74 \% \mathrm{H}_{2} \mathrm{SO}_{4}$ to solubilize polysaccharides and to deaminate chitin. The whole polysaccharide content was then measured at $540 \mathrm{~nm}$ after adding $5 \mathrm{ml}$ anthrone (Chung \& Nickerson, 1954). Glucose solutions were used as standards.

Electron microscopy. The material, suspended in water, was placed on a Formvarcoated copper grid. After drying, the specimens were shadowed with carbon/platinum or negatively stained with $\mathrm{r} \%$ phosphotungstate at $\mathrm{pH} 7 \cdot \mathrm{I}$, and examined in a Tesla table-top microscope.

$X$-ray diffraction. X-ray powder diagrams were made by irradiation of specimens that were $0.5 \mathrm{~mm}$ thick in the direction of the beam, using nickel-filtered $\mathrm{CuK}$ radiation from a Philips fine-focus tube at $38 \mathrm{kV}$ and $25 \mathrm{~mA}$. Flat film (Ilford Ilfex or Kodak Kodirex) was placed $40 \mathrm{~mm}$ from the specimen. Collimators were pinhole type, $50 \mathrm{~mm}$ long and $0.5 \mathrm{~mm}$ wide, or $0.25 \mathrm{~mm}$ wide where line resolution was important. Densitometer curves were made of the diagrams with a Joyce-Loebl Mk III densitometer with the effective slit $0.2 \times 2 \mathrm{~mm}$. In redrawing the curves for reproduction, grain effects were smoothed out.

\section{RESULTS}

\section{Electron microscopy}

Electron micrographs of a number of specimens obtained as described in the preceding section are shown in Figs. I to I0. Fig. I shows a typical cleaned fibrillar net, without remnants of the old wall. The microfibrils, about $20 \mathrm{~nm}$ wide, were aggregated into bands of variable width (cf. Kopecká et al. 1967), frequently around roo nm wide and up to about $2 \mu \mathrm{m}$ long. They were fairly straight between the junctions of the bundles. Exceptionally broad bands, up to about $500 \mathrm{~nm}$ wide and $4 \mu \mathrm{m}$ long, are shown in Fig. 2. Those in Fig. 3 were more highly magnified and negatively stained, showing a core of the microfibrils about Io $\mathrm{nm}$ wide not penetrated by the stain. Free ends of the latter were seldom found. The appearance of these net structures was unaffected by heating in distilled water or $2 \%$ 


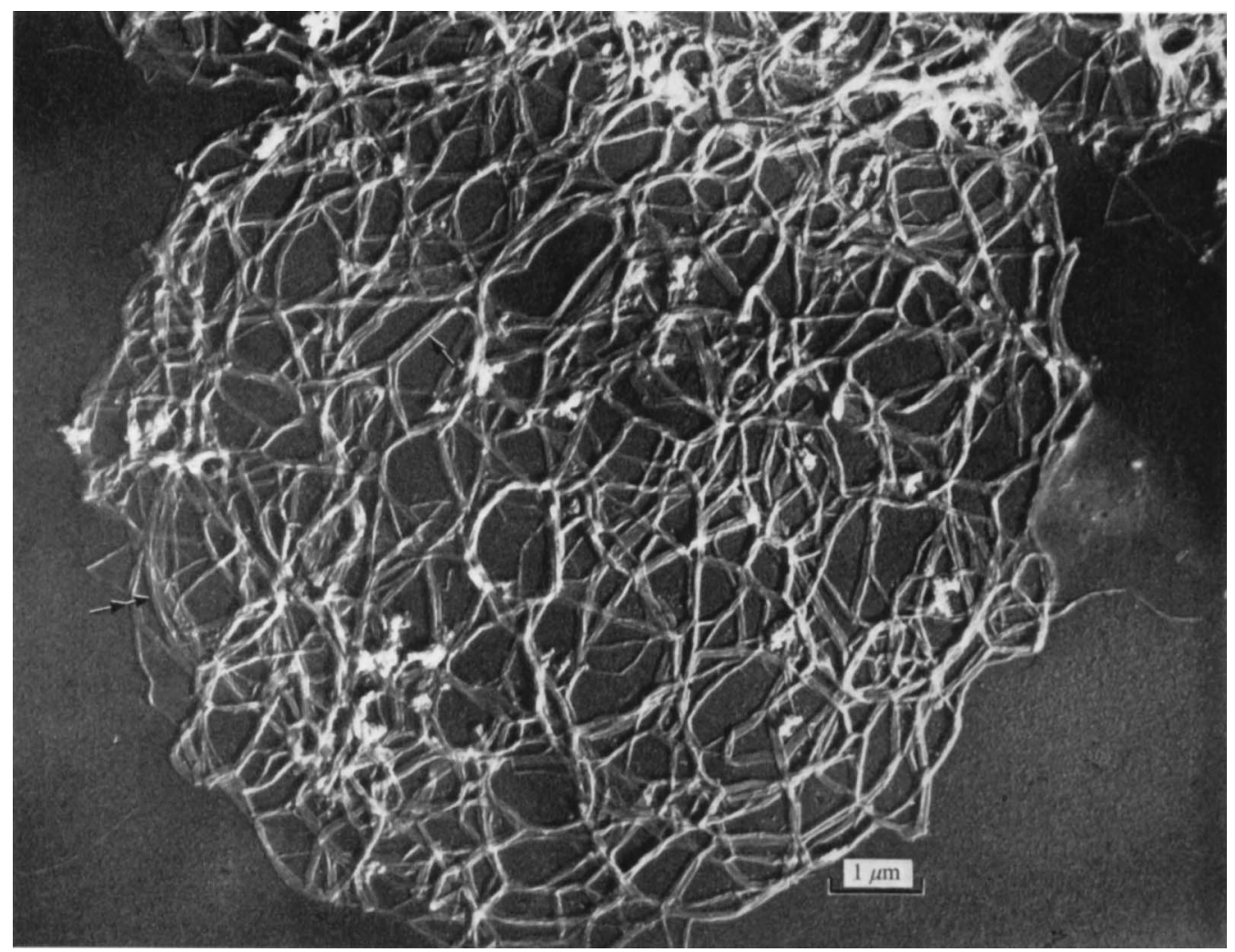

Fig. I. Protoplast fibrillar net purified with trypsin, ethanol and water, shadowed with carbon/platinum. Arrows indicate band formations where they are $100 \mathrm{~nm}$ wide $(\longrightarrow)$ and $2 \mu \mathrm{m}$ long $(\rightarrow)$.

$\mathrm{HCl}$, by treatment with cold $30 \% \mathrm{HCl}$ or chitinase, or by extraction with hot acetic acid. Nevertheless, about $20 \%$ of the polysaccharide was removed by chitinase, and possibly more was removed by $2 \% \mathrm{HCl}$ at $100^{\circ} \mathrm{C}$ (see Table I). Figure 3 illustrates a chitinase-treated sample.

The partly digested old wall fragments were usually shaped like whole cells without the poles (Fig. 4). They showed no surface structure, but after treatment with $\mathrm{HCl}$ at $100{ }^{\circ} \mathrm{C}$ (Fig. 5) they had the microfibrillar appearance of hydroglucan (Houwink \& Kreger, 1953). $\mathrm{X}$-ray diffraction (Fig. I $d$, curve $\mathrm{C}$ ), as discussed later, confirmed this and revealed that they also contained chitin (more than in normal walls). Figure $5(b)$ shows that the microfibrils were much shorter (about 100 to $200 \mathrm{~nm}$ ) than those of the protoplast nets, while the meshes of the net were much smaller (Fig. 5a). The width of each fibril was about 20 to $25 \mathrm{~nm}$ (Fig. $5 a$ ), or 12 to $20 \mathrm{~nm}$ after negative staining (Fig. $5 b$ ).

Fig. 2. Fibrillar net treated as in Fig. I, showing extreme band formation: $500 \mathrm{~nm}$ wide $(\longrightarrow)$ and $4 \mu \mathrm{m}$ long $(\rightarrow)$.

Fig. 3. Part of fibrillar net after chitinase treatment and negative staining with phosphotungstate.

Fig. 4. Walls partly digested by snail enzymes, shadowed with carbon/platinum. The poles are missing. No surface structure.

Fig. 5. ' $\mathrm{HCl}$ walls' prepared from partly digested walls. (a) Shadowed with carbon/platinum; densely intertwined, short microfibrils of hydroglucan. (b) Microfibrils, negatively stained. 


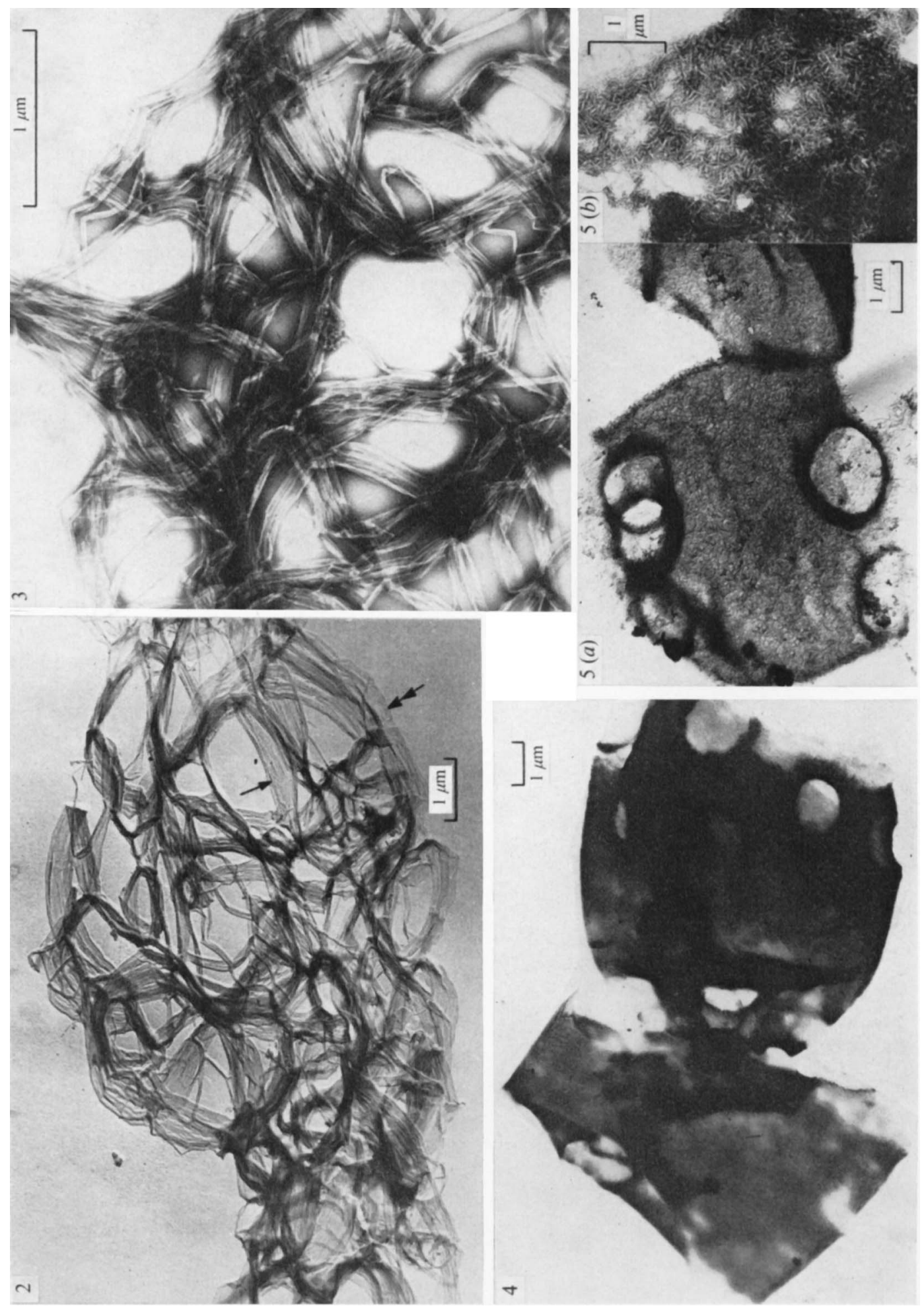


Table I. Appearance in the electron microscope, and residual polysaccharide of the fibrillar nets after various treatments

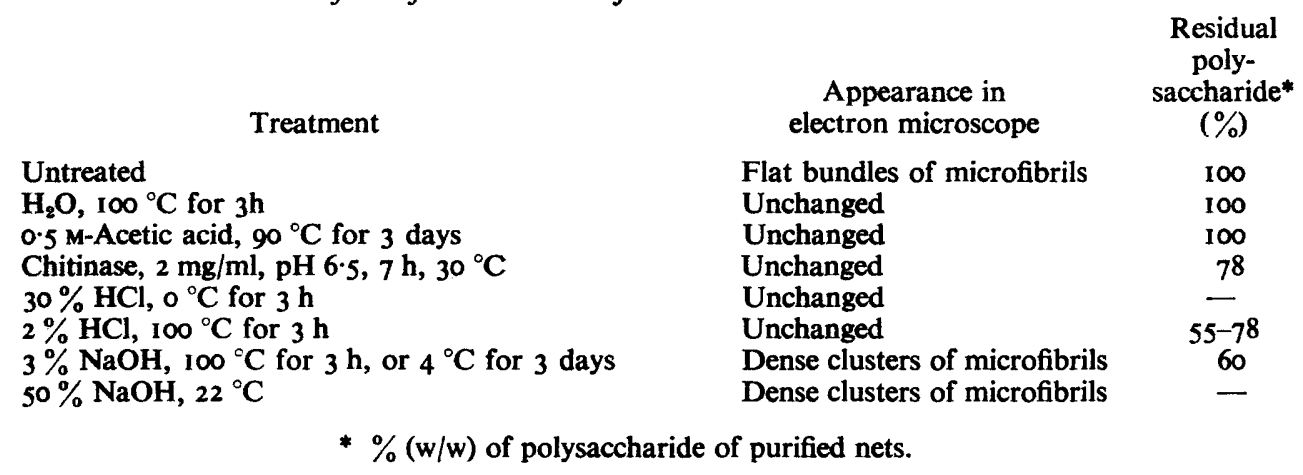

Table 2. Scheme of fractionation of purified fibrillar nets with alkali

Fibrillar nets in $3 \% \mathrm{NaOH}$ at $4{ }^{\circ} \mathrm{C} \rightarrow$ Centrifugation
$\begin{gathered}\text { Sedimentable fraction } \\ \begin{array}{c}\text { Alkali-insoluble clusters of } \\ \text { glucan with chitin }\end{array}\end{gathered}$

Fragments of normal walls were obtained from the supernatant of a dispersed and partly sedimented sample of walls rubbed with sand grains (Fig. 7). Negatively stained, they exhibited a fine network of single microfibrils, about 7.5 to $10 \mathrm{~nm}$ thick, forming meshes about 20 to $60 \mathrm{~nm}$ wide. A similar structure was seen throughout the inner part of the walls (Fig. 8 and inset to Fig. 7) after treatment with an endo- $\beta$ - $(\mathrm{I} \rightarrow 3)$-glucanase by the methods described by Kopecká, Phaff \& Fleet (1974).

After treatment of protoplast nets with dilute alkali, their structure had disappeared; the residue that remained constituted about $60 \%$ dry wt of the nets (Table I). It consisted of clusters, about $2.5 \mu \mathrm{m}$ in diameter, of densely intertwined microfibrils about $15 \mathrm{~nm}$ wide, and amorphous material (Fig. 6).

When the nets were extracted with alkali in the cold and the alkali was neutralized (Table 2), a precipitate of microfibrils about $20 \mathrm{~nm}$ wide was obtained which tended to aggregate (Fig. 9). Figure Io shows the same material after negative staining; widths of the microfibrils were about the same but aggregation lengthwise was not apparent.

\section{$X$-ray diffraction}

The X-ray diagrams from the fibrillar net samples, their products of extraction and some reference samples are given in Fig. II, in the form of radial density curves. The crystal spacings derived from the peaks of the curves are compiled in Table 3.

The nature of the microfibrils. The X-ray diagrams (Fig. I I $a$, curves A to D) of specimens of washed native nets show a number of relatively sharp X-ray diffraction rings, partly as free density peaks in a region of slight diffuse scattering (peaks I to 3 ) and partly as small peaks superimposed on a diffuse ring of high density. Hence, the nets contained microcrystalline material. In this respect they differed from normal walls or partly digested 

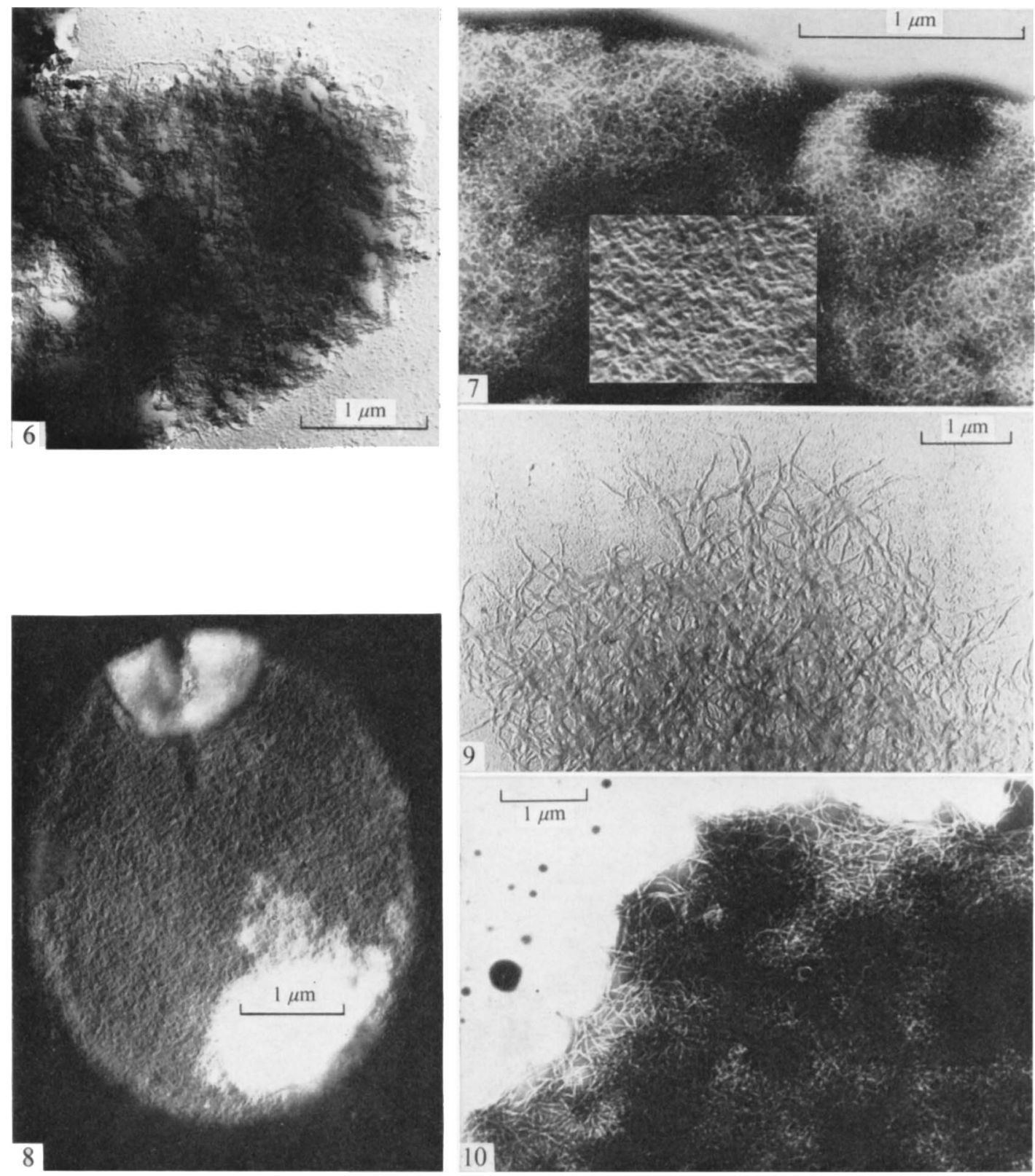

Fig. 6. Residue of nets treated for $3 \mathrm{~h}$ with $3 \%(\mathrm{w} / \mathrm{v}) \mathrm{NaOH}$ at $100{ }^{\circ} \mathrm{C}$, shadowed with carbon/ platinum. Clusters of partly microfibrillar material.

Fig. 7. Fragment of normal wall disintegrated with sand grains, negatively stained. Inset shows part of Fig. 8 enlarged to the same scale. Fine network of microfibrils.

Fig. 8. Normal wall treated with endo- $\beta$ - $(1 \rightarrow 3)$-glucanase, shadowed with carbon/platinum. Fine network of microfibrils throughout the inner part of the wall.

Fig. 9. Alkali-soluble glucan from fibrillar nets, dissolved at $4{ }^{\circ} \mathrm{C}$ and reprecipitated. Aggregates of microfibrils, shadowed with carbon/platinum.

Fig. IO. As Fig. 9 but negatively stained. Microfibrils not aggregated. 

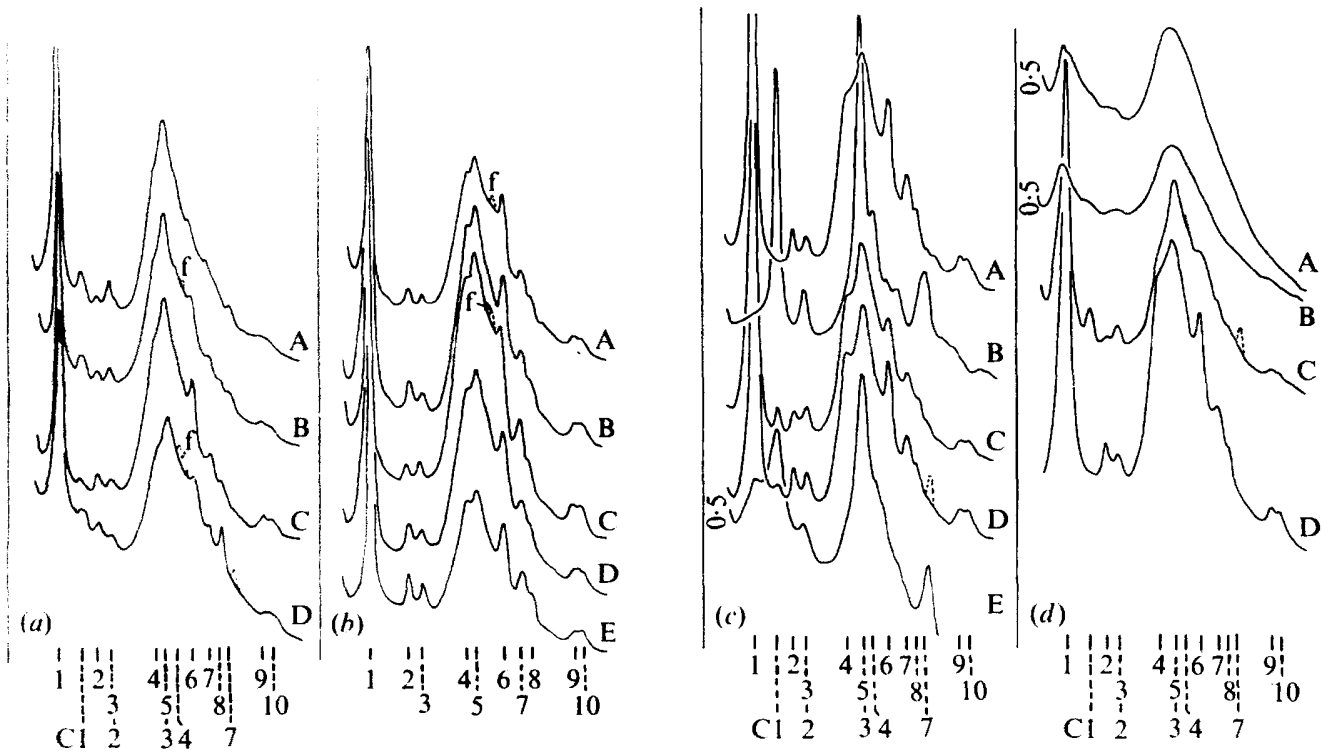

Fig. 11. Densitometer curves from X-ray powder diagrams of specimens of fibrillar nets, their residues and products of extraction, and from diagrams used for reference purposes. The vertical lines connect the centres of the diagrams. Curves from diagrams taken with a collimator $0.5 \mathrm{~mm}$ wide are labelled ' 0.5 '. The crystal spacings represented by the peaks are compiled in Table 3 . The peaks corresponding to those of hydroglucan or paramylon have been numbered 1 to 10 , and those corresponding to chitin peaks are designated $\mathrm{CI}_{\mathrm{I}}$ to $\mathrm{C}_{7}$. The small peaks drawn in broken lines correspond to the spacings of the most intense reflexions of either $\alpha$-quartz or aliphatic products, which are contaminations ( $\mathrm{f}=$ aliphatic line). (a) Curves $\mathrm{A}, \mathrm{B}$ and $\mathrm{C}$ are from samples $\mathrm{I}$, 2 and 3 respectively of fibrillar nets, and curve $D$ from nets grown on chitinase-pretreated protoplasts. (b) Curves A, B and C are from samples I, 2 and 3 respectively after extraction with cold $30 \% \mathrm{HCl}$, curve $\mathrm{D}$ from sample 3 after chitinase treatment, and curve $E$ from paramylon. (c) Curve A: hydroglucan (walls of Schizosaccharomyces octosporus treated for $3 \mathrm{~h}$ with boiling $2 \% \mathrm{HCl}$ ). Curve B: chitin (extracted from walls of Penicillium notatum). Curve C: hydroglucan (see A) mixed with chitin (see B) in the proportions 9: I (dry wt). Curve D: walls of baker's yeast treated for $3 \mathrm{~h}$ with boiling $2 \% \mathrm{HCl}$. Curve E: precipitate from $30 \% \mathrm{HCl}$ extract from fibrillar nets sample $\mathrm{I}$. (d) Curve A: normal walls of baker's yeast. Curve B: partly digested wall fragments from protoplasts used in the preparation of net sample $\mathrm{I}$. Curve $\mathrm{C}$ : ' $\mathrm{HCl}$ walls' prepared from the same. Curve D: material precipitated from cold alkali extract from nets and treated for $I \mathrm{~h}$ with boiling $2 \% \mathrm{HCl}$.

normal walls collected from a protoplast sample (cf. Methods) because these produced curves without sharp peaks (Fig. I I $d$, curves A and B). The peaks of the net samples, therefore, came from the nets themselves and not from contaminating old walls.

The nature of the components is given by the crystal spacings represented by the peaks in the curves. The $\mathrm{Cr}_{1}$ and $\mathrm{C}_{7}$ peaks correspond to spacings of about 0.950 and $0.338 \mathrm{~nm}$, respectively, which belong to the characteristic set of chitin spacings (Fig. I $c$, curve $\mathrm{B}$ and Table 3), while those corresponding to the other peaks are found in hydroglucan and paramylon (Fig. I c $c$, curve A, Fig. I $b$, curve E and Table 3), both of which consist of $\beta$-( $1 \rightarrow 3$ )linked glucan. Hence, these types of glucan and chitin probably form the two crystalline components of the nets. The low $C_{1}$ peak in Fig. I I (a), curves $C$ and D, and the absence of a $C_{7}$ peak show that these nets had less chitin than the two other samples.

Extraction of chitin. The above suggestions have been verified by selective extraction of the chitin by either $30 \% \mathrm{HCl}$ in the cold or by chitinase treatment. The results are shown in Fig. I I $(b)$, curves A, B and C, which refer to the same samples as Fig. I I (a), curves A, B and 
Table 3. Survey of crystal spacings (nm) represented by the peaks in the densitometer curves of Fig. I I and referable to glucan and chitin

$\begin{array}{lllllllllllll}\text { Glucan: I } & & 2 & 3 & 4 & 5 & & 6 & 7 & 8 & & 9 & \text { I0 } \\ \text { Chitin: } & \text { CI } & & \mathrm{C}_{2} & & \mathrm{C}_{3} & \mathrm{C}_{4} & & & & \mathrm{C}_{7} & & \end{array}$ Curve

Fig. II $(a)$

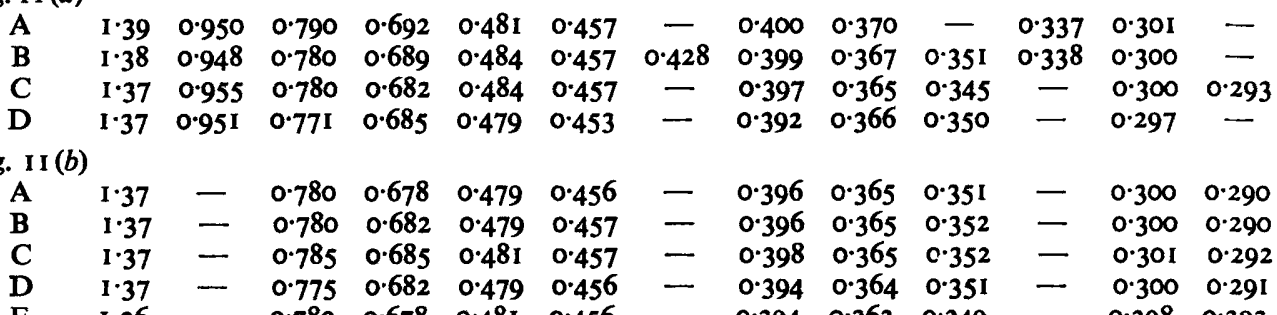

Fig. 11 (c)

$\begin{array}{llllllllllllll}\text { A } & 1.37 & - & 0.780 & 0.682 & 0.497 & 0.450 & - & 0.396 & 0.364 & 0.350 & - & 0.300 & 0.292 \\ \text { B } & - & 0.948 & - & 0.698 & - & 0.459 & 0.428 & - & - & - & 0.339 & - & - \\ \text { C } & 1.37 & 0.950 & 0.780 & 0.685 & 0.499 & 0.455 & - & 0.394 & 0.365 & 0.349 & 0.338 & 0.299 & 0.290 \\ \text { D } & 1.37 & 0.955 & 0.780 & 0.682 & 0.501 & 0.450 & - & 0.396 & 0.364 & 0.351 & - & 0.300 & 0.292 \\ \text { E } & - & 0.948 & - & 0.700 & - & 0.457 & - & - & - & - & 0.335 & - & -\end{array}$

Fig. $11(d)$

$\begin{array}{llllllllllllll}\text { A } & \text { I.43 } & - & - & - & - & 0.462 & - & - & - & - & - & - & - \\ \text { B } & 1.49 & 0.955 & - & - & - & 0.456 & - & - & - & - & - & - & - \\ \text { C } & 1.39 & 0.942 & 0.780 & 0.689 & 0.505 & 0.452 & - & 0.398 & 0.365 & 0.345 & - & 0.298 & - \\ \text { D } & 1.37 & - & 0.775 & 0.682 & 0.491 & 0.454 & - & 0.394 & 0.364 & 0.350 & - & 0.299 & 0.292\end{array}$

C, but after extraction with $30 \% \mathrm{HCl}$. Figure I I (b), curve D corresponds to Fig. I I $(a)$, curve $C$, but after incubation of the material with chitinase.

With all samples, peak $C_{1}$ disappeared after extraction, and also the shoulders corresponding to $\mathrm{C}_{7}$ in Fig. I I (a) curves A and B have disappeared in Fig. II (b) curves A and B. The much smaller difference in height between peaks 4 and 5 in Fig. I I $(b)$ than in Fig. I I $(a)$ is explained by the absence, in Fig. II (b), of the contribution of chitin reflexion $\mathrm{C}_{3}$ to the height of peak 5. These observations confirm that part of the $\mathrm{X}$-ray patterns of the unmodified nets is due to chitin.

That the material extracted by $30 \% \mathrm{HCl}$ was chitin was confirmed by the $\mathrm{X}$-ray diagram (Fig. I $c$, curve $\mathrm{E}$ ) of the precipitate obtained by dilution of the $\mathrm{HCl}$ extract from one of the net samples. Comparison with the tracing of authentic chitin (Fig. I I $c$, curve B) shows that the main peaks produced by the precipitate corresponded to those of chitin. In Fig. II (c), curve $\mathrm{E}$, the diffuse background and lower peak to the left of $\mathrm{C}_{\mathrm{I}}$ indicate contamination of the precipitate.

The X-ray spacings of the nets after chitin extraction correspond closely with those of paramylon or hydroglucan (compare Table 3 with Fig. I $b$, curve E, and Fig. I I $c$, curve A). There is a small difference between hydroglucan and paramylon in the intensity distribution at the top of the main peak. This is caused by small differences in the positions of peaks 4 and 5. In hydroglucan (Fig. I I $c$, curve A) these correspond to 0.497 and $0.450 \mathrm{~nm}$ respectively, whereas in paramylon (Fig. I $b$, curve E) they correspond to 0.481 and $0.456 \mathrm{~nm}$. In all the chitin-free net samples (Fig. I $b$, curves $A$ to $D$ ), the spacings 4 and 5 vary from 0.479 to $0.48 \mathrm{Im}$ and from 0.456 to $0.457 \mathrm{~nm}$, respectively. They therefore correspond very closely to those of paramylon, whereas they show a systematic deviation of about -0.02 
and $+0.006 \mathrm{~nm}$ respectively from the values found in hydroglucan. Since the latter might be supposed to be accidental deviations in the hydroglucan sample in question (prepared from cell walls of Schizosaccharomyces octosporus), the curve from a sample of hydroglucan prepared from baker's yeast walls is shown for comparison in Fig. II $(c)$, curve D. Its spacings 4 and 5 (Table 3) showed nearly the same deviations from those of paramylon as are observed in Fig. I I (c), curve A. Hence the crystalline glucan moiety of the net microfibrils shows the paramylon structure, which has slightly different spacings 4 and 5 from those of hydroglucan.

The difference in the position of peak 5 in the hydroglucan and paramylon diagrams may be obscured by contamination of hydroglucan with chitin, because of the overlap of peak 5 by the chitin peak $C_{3}$. The slightly increased spacings found for peak 5 in Fig. I I (c), curve $C$, and Fig. I I $(d)$, curve $C$, may therefore have been due to the chitin content of the samples in question giving rise to a shift in the direction of the $0.459 \mathrm{~nm}$ position of $\mathrm{C}_{3}$. Their glucan was nevertheless clearly identified as hydroglucan by the peak 4 spacings.

Extraction with alkali. The soluble fraction of the nets in cold alkali precipitated if the solution was neutralized (Table 2, Figs. 9 and I0). Though microfibrillar, the precipitate did not give an $\mathrm{X}$-ray pattern with sharp rings. It resembled the diagram of isolated walls (Fig. I I $d$, curve A) but the density of the broad peaks was greater. The crystallinity could be restored, however, by treatment with boiling $2 \% \mathrm{HCl}$ for $\mathrm{I} \mathrm{h}$, as is shown by the density curve (Fig. I I $d$, curve D). The spacings measured on this curve correspond, with some minor variations, to those of hydroglucan and paramylon, which shows that the soluble fraction of the nets consists of $\beta$ - $(\mathrm{I} \rightarrow 3)$ glucan. Spacings 4 and 5 do not correspond to either the paramylon or the hydroglucan modification; both have intermediate values. This might be because the alkaline glucan solution was partly colloidal and groups of chains retained the normal paramylon arrangement, acting as primers during the process of recrystallization.

Preliminary X-ray data about the alkali-insoluble clusters (Fig. 6) suggested that this glucan corresponds to that of the normal wall.

\section{The chitin content of the nets}

By extraction. Extraction with $30 \% \mathrm{HCl}$ and reprecipitation of the chitin was carried out with fractions of samples $\mathrm{I}$ and 2 ( $\mathrm{I} \cdot 4$ and $\mathrm{I} \cdot 65 \mathrm{mg}$ dry wt, respectively), of which 39 and $36 \%$ dissolved. Dilution of the acid yielded a precipitate in both cases. That for sample 2 was $24.2 \%$ dry wt of the original fraction and produced the X-ray pattern represented by Fig. I I (c), curve E. This indicated that the only microcrystalline constituent of the precipitate was chitin, heavily contaminated by amorphous material and forming roughly half the precipitate. There was no evidence for any chitin in the residues of the extraction with $30 \% \mathrm{HCl}$ (Fig. I I $b$, curves A, B and C), so sample I probably contained about $\mathrm{I} 2 \%(\mathrm{w} / \mathrm{w})$ chitin.

From $X$-ray intensities. The intensities of the $\mathrm{X}$-ray reflexions of a crystalline component of a powdered specimen depend on the percentage of the component contained in the specimen. Therefore the intensities of the chitin reflexions produced by the nets indicate their contents of microcrystalline chitin. A standard sample containing $10 \%$ dry wt chitin was prepared by mixing chitin (from cell walls of Penicillium notatum) with a sample of hydroglucan from Sch. octosporus, which contains no chitin (Roelofsen \& Hoette, 195I; Kreger, 1954). The X-ray patterns of the respective samples are represented by the density curves C, B and A in Fig. I I (c). The CI peak was the only chitin reflexion available for comparison since all others interfere with hydroglucan diffractions. Since the sizes of the $C_{I}$ 


\section{Table 4. Determination of percentages of crystalline chitin in net samples} (\% dry wt of purified nets) from peak area ratios in densitometer curves

(a) Ratios $I_{\mathrm{C}_{1}} / I_{\mathrm{M}}$ in curves from X-ray diagrams taken from artificial mixtures of chitin and hydroglucan. (b) Ratios $I_{\mathrm{C} 1} / I_{\mathrm{M}}$ in curves of $\mathrm{X}$-ray diagrams taken from chitin-containing net samples, with corresponding chitin percentages as determined by graphical interpolation from the data in (a). Further explanation is given in the text.

(a) Artificial mixtures

$\begin{array}{lc}\begin{array}{c}\text { Chitin } \\ (\%)\end{array} & 100 I_{\mathrm{C} 1} / I_{\mathrm{MC}} \\ \text { I0 (Fig. I I c, C) } & 1 \cdot 25 \\ 20 & 2.65 \\ 30 & 4.2 \\ 40 & 6.0\end{array}$

(b) Nets and walls

$\begin{array}{lcr}\text { Curve } & 100 I_{\mathbf{C} 1} / I_{\mathbf{M}} & \begin{array}{c}\text { Chitin } \\ (\%)\end{array} \\ \text { Fig. I I }(a), \text { A } & 1.98 & 15.5 \\ \text { Fig. I I }(a), \text { B } & 1.54 & 12.5 \\ \text { Fig. I }(a), \text { C } & 0.36 & 3.0 \\ \text { Fig. I I }(a), \text { D } & 0.83 & 6.7 \\ \text { Fig. I I }(c), \text { D } & 0.56 & 4.5 \\ \text { Fig. I I }(d), \text { C } & 2.14 & 16.5\end{array}$

peaks produced by the net samples I and 2 (Fig. I $a$, curves A and B) were very slightly higher than that shown in Fig. II $(c)$, curve $C$, these samples contained slightly more than $10 \%$ (w/w) chitin.

A more accurate determination may be made taking into account (i) that in quantitative determinations the peak area should be used because peak height may be affected by variability in crystallite size, (ii) that comparison of intensities on different X-ray diagrams from different samples requires the elimination of effects of variability in exposure, specimen thickness and film development. For this elimination the chitin line intensity may be related to an intensity that is affected by only these factors, e.g. the intensity of a line from a suitable component added in fixed proportion to the net samples and standard. However, because only small quantities of the nets were available, such additions could not be made with the required accuracy. The ratio of chitin to glucan may nevertheless be determined from the ratio of their line intensities, which is unaffected by factors which affect all line intensities proportionately.

For determining by X-ray diffraction the chitin to hydroglucan ratio in cell wall residues, D. R. Kreger and J. Jelsma (unpublished) elaborated an empirical graph. This represents the ratio of the surfaces of the $\mathrm{C}_{\mathrm{I}}$ and main peak, which contains the glucan reflexions 4 to 8 , in X-ray density curves of chitin-hydroglucan mixtures, as a function of their chitin: glucan ratio. Intensity ratios are given in Table $4(a)$, in which $I_{\mathrm{C} 1}$ and $I_{\mathrm{M}}$ represent the surfaces of the $\mathrm{CI}_{\mathrm{I}}$ and main peaks respectively. In Table $4(b)$ the $I_{\mathrm{C} 1}: I_{\mathrm{M}}$ ratios are given for all the curves in Fig. I that show a $C_{1}$ peak. The chitin:glucan ratios of the samples in question (as percentages of chitin of the combined constituents) are given in the last column and have been derived from the data of Table $4(a)$ by graphical interpolation.

\section{DISCUSSION}

\section{Formation of glucan microfibrils}

The protoplast nets. Since $\beta$ - $(\mathrm{I} \rightarrow 3)$ glucan crystallized in vitro in the form of hydroglucan consists of short, rod-like microfibrils (Fig. $5 b$; see also Figs. 7 and 8 of Houwink \& Kreger, 1953), which are about 100 to $200 \mathrm{~nm}$ long, the question arises why microfibrils made of the same glucan by the protoplasts are at least $600 \mathrm{~nm}$ long (Figs. I, 3) and may even be up up to $4 \mu \mathrm{m}$ long (Fig. 2). The reprecipitated protoplast glucan also forms long microfibrils (Fig. 10). The difference might indicate a different degree of polymerization. Indeed, values 
around 28 or 40 monomers have been reported for hydroglucan (Barry \& Dillon, 1943; Hassid, Joslyn \& McCready, I94I), whereas the molecular weight of the alkali-soluble net glucan has been determined as $1 \cdot I \times 10^{5} \pm 0.3 \times 10^{5}$ (Eddy \& Woodhead, I968), corresponding to a chain length of about 600 glucose groups.

Hydroglucan represents the $\beta$ - $(\mathrm{I} \rightarrow 3)$-chains of the branched glucan of the normal wall (for details of the structure of this glucan see Manners, Masson \& Patterson, 1973) after hydrolysis of their $\beta$-(I $\rightarrow 6)$-links at the points of branching. The absence of a fraction of the long, unbranched chains in the normal glucan indicates that, during its formation, $(\mathrm{I} \rightarrow 6$ )-linking synthetase is more active in forming points of branching than in net formation. This suggests that this enzyme is more easily washed away from the plasma membrane or otherwise inactivated by the liquid medium of the protoplast culture than is the (I $\rightarrow 3$ )synthetase.

The nets could not have been formed if the $(\mathrm{I} \rightarrow 3)$-linked chains had been removed in some way from the protoplast surface by the culture liquid. Because of their apparent adherence to the membrane, microfibril formation and crystallization of the chains cannot be explained from the physico-chemical conditions in a solution of free chains. In addition, microfibrils formed by these chains in a solution (Fig. 10) were clearly different from those of the nets: more curved, not bundled, less crystallized, and if the crystallinity was restored the crystalline part did not have the characteristic paramylon structure (Fig. I I $d$, curve D). Hence the microfibrils of the nets must be formed in a different manner.

Precisely how the in vivo assembly of the chains into microfibrils takes place is not known, but it seems likely that enzymes in the plasmalemma play a role. If synthesis and crystallization were effected simultaneously by enzymes, this might explain the slightly different packing of the chains from those crystallized in vitro. It would imply that the chains arise on enzyme-synthesizing sites which are in close proximity to one another. The alkali-insoluble glucan remaining as clusters must form part of the net microfibrils (since no other structures were observed) and is probably synthesized along with the soluble part. The postulated enzymes may be embodied in the granules (of about the same diameter as the microfibrils) which abound on or in the plasmalemma of protoplasts and normal cells (for a review, see Nečas, 1971).

Bundle formation of the microfibrils seems to be attributable to the crystalline component because the crystallinity, in combination with the length of the chains, can produce a certain rigidity and straightness in the fibrils. Such properties, perhaps in combination with free lattice forces, would favour aggregation. The bundles are certainly not simply the result of the drying process like the aggregation shown by the microfibrils in Fig. 9, since the nets always showed the bundles; this has also been shown in freeze-etching preparations (Nečas, 1971). The wide meshes can be explained as places cleared of microfibrils by their aggregation.

Normal walls. The earlier data, mentioned in the Introduction, indicate the presence, at least locally, of a fine microfibrillar network in the normal wall; this was confirmed and extended by the electron micrographs of Figs. 7 and 8. Both Figures refer to the inner layer of the wall containing the main glucan fraction, and show the absence here of bands of long microfibrils. This feature, and also the poor crystallinity (Fig. I $d$, curve A) of this glucan, are comprehensible from its branched structure and the absence of the unbranched fraction which seems to determine, mainly by its crystallinity, the characteristic structure of the protoplast nets.

\section{Chitin}

Crystallinity in nets and normal walls. In the nets, the crystallinity is clearly demonstrated by the appearance of the CI peaks in Fig. II (a), curves A to D. However, this peak is absent 
from normal walls (Fig. I I $d$, curve A) because here there is too little chitin (less than I $\%$ ) for any observable diffraction. This low chitin content appears from the $4 \%(w / w)$ chitin in the hydroglucan residue (Table 4 ) representing about $20 \%$ of the wall (Houwink \& Kreger, 1953) and in which the chitin, by treatment of the walls with boiling $2 \% \mathrm{HCl}$, has accumulated and turned crystalline (Fig. I I $c$, curve D). Nevertheless, that crystallinity in normal walls is poor may be deduced from the sample of walls partly digested by snail enzyme (Fig. 4), as the following reasoning shows: treatment of these partly digested walls with boiling $2 \% \mathrm{HCl}$ yielded hydroglucan (Fig. 5) and crystallized chitin (Fig. I $d$, curve C). The latter constituted about $16 \%$ of the residue (Table 4), i.e. about four times as much as in hydroglucan residues from normal walls. As the helicase probably removed, besides much glucan, all the mannan from the original walls, the digested sample must have had about eight times the chitin content of normal walls. If crystalline, this would have given a clear Cr peak in Fig. I I (d), curve B, but there is only a faint indication of a peak. Other evidence of low crystallinity of chitin in the cell walls of baker's yeast has been given by Beran, Řeháček \& Seichertová (1970) and in fungi with highly chitinous walls by Kreger (1954) who ascribed it to complex formation.

The apparent crystallinity of the chitin in untreated nets is remarkable. It could be explained, as for the glucan chains, by the washing-out of an extracellular complex-forming factor and the ability of the plasma membrane to produce crystalline chitin in the absence of this factor.

The chitin content. The increased chitin:glucan ratio of the nets could either be because cultural conditions induced increased chitin synthesis, or because part of the $\beta$ - $(\mathrm{I} \rightarrow 3)$ glucan synthetase in normal cells is less firmly attached to the plasma membrane than chitin synthetase and consequently does not contribute to the net formation as it is removed by the culture liquid. The second possibility seems to be more likely, because it is not at once clear what factor in the culture medium would induce the cell to increase its chitin synthetic activity about threefold, whereas (i) $\beta$-(I $\rightarrow 3$ )-linking activity has been observed in purified wall preparations of a fungus, i.e. outside the plasma membrane (Wang \& Bartnicki-Garcia, I966), and (ii) chitin synthetase is not located outside the plama membrane (Keller \& Cabib, 197I) although it can be released by experimental conditions (Ruiz-Herrera \& Bartnicki-Garcia, 1974).

Consequently, the constitution of the nets may be explained by differences in adherence to the plasma membrane for chitin synthetase, $\beta$ - $(\mathrm{I} \rightarrow 3)$ - and $\beta$-(I $\rightarrow 6)$-glucan synthetase, respectively, with decreasing adherence in this order.

The chitin: glucan ratio in one of the net samples (Fig. I I $a$, curve C) is much lower than in the others. In normal cell populations the chitin content also varies, and depends on the number of bud scars in the population (Beran \& Rehaček, 1969). Hence, chitin synthetic activity in a population should be associated with the growth phase, and in a protoplast culture with the growth phase of the yeast culture from which they originate. Indeed, Hasilik (1974) showed that chitin synthase can be detected in batch cultivation of $S$. cerevisiae only during exponential growth. In sample 3, producing curve C of Fig. II (a), this phase had not been controlled and may have been in transition to the stationary phase.

Finally, the electron micrographs of the nets do not reveal any particles that by morphological differentiation may be identified as chitin.

The authors thank Professor O. Nečas for his warm interest and Dr J. A. Barnett, Norwich, for improving the English. 


\section{REFERENCES}

Bacon, J. S. D., Gordon, A. H., Jones, D., TAylor, I. F. \& Webley, D. M. (1970). The separation of $\beta$-glucanases produced by Cytophaga johnsonii and their role in the lysis of yeast cell walls. Biochemical Journal 120, 67-78.

Barry, V. C. \& Dillon, T. (1943). The glucan of the yeast membrane. Proceedings of the Royal Irish Academy B 49, 177-185.

BerAN, K. \& ŘEHÁČEK, J. (1969). Content and structure of chitin in cell walls of the yeast Saccharomyces cerevisiae. Antonie van Leeuwenhoek 35, Supplement: Yeast Symposium 1969, B 3.

Beran, K., ReháČEK, J. \& Seichertové, O. (1970). Infrared spectral analysis of the yeast cell wall. The application of the method in the study of chitin in cell walls of the yeast Saccharomyces cerevisiae. In Yeast Protoplasts. Proceedings of the Second International Symposium on Yeast Protoplasts, pp. 171-182. Edited by O. Nečas and A. Svoboda. Brno: J. E. Purkyně University Press.

BOWDEN, J. K. \& HodGson, B. (1970). Evidence against the presence of fibres or chemically distinct layers in the cell wall of Saccharomyces. Antonie van Leeuwenhoek 36, 81-108.

Chung, C. W. \& Nickerson, W. J. (1954). Polysaccharide synthesis in growing yeasts. Journal of Biological Chemistry 208, 395-407.

Eddy, A. A. \& Williamson, D. H. (1959). Formation of aberrant cell walls and spores by growing yeast protoplasts. Nature, London 183 , I IOI-I 104.

EDDY, A. A. \& WoOdhEAD, J. S. (1968). An alkali-soluble glucan fraction from the cell walls of the yeast Saccharomyces carlsbergensis. FEBS Letters I, 67-68.

Hasiuk, A. (1974). Inactivation of chitin synthase in Saccharomyces cerevisiae. Archives of Microbiology ror, 295-301.

Hassid, W. Z., Joslyn, M. A. \& McCready, R. M. (I94I). The molecular constitution of an insoluble polysaccharide from yeast, Saccharomyces cerevisiae. Journal of the American Chemical Society 63, 295-298.

HouwINK, A. L. \& KREGER, D. R. (1953). Observations on the cell walls of yeasts. An electron microscope and X-ray diffraction study. Antonie van Leeuwenhoek 19, I-24.

Keller, F. A. \& Cabib, E. (197I). Chitin and yeast budding. Properties of chitin synthetase from Saccharomyces carlsbergensis. Journal of Biological Chemistry 246, 160-166.

KopeCKÁ, M., CTVRTNí̌EK, O. \& NeČAS, O. (1967). Formation and properties of fribrillar network formed in yeast protoplasts as the first step of biosynthesis of cell wall. In Symposium über Hefe-Protoplasten, pp. 73-76. Edited by R. Müller. Berlin: Akademie-Verlag.

KopeckÁ, M., Phaff, H. J. \& Fleet, G. H. (1974). Demonstration of a fibrillar component in the cell wall of the yeast Saccharomyces cerevisiae and its chemical nature. Journal of Cell Biology 67, 66-76.

KREGER, D. R. (1954). Observations on cell walls of yeasts and other fungi by X-ray diffraction and solubility tests. Biochimica et biophysica acta 13, I-9.

KREGER, D. R. \& KopeCKÁ, M. (1973). On the nature of the fibrillar nets formed by protoplasts of Saccharomyces cerevisiae in liquid media. In Yeast, Mould and Plant Protoplasts. Proceedings of the Third International Symposium on Yeast Protoplasts, Salamanca, pp. I $17-1$ 30. Edited by J. R. Villanueva, I. García-Acha, S. Gascón and F. Uruburu. London: Academic Press.

MANners, D. J. \& Masson, A. J. (1969). The structure of two glucans from yeast-cell walls. FEBS Letters 4, 122-124.

Manners, D. J., Masson, A. J. \& Patterson, J. C. (1973). The structure of a $\beta$-(I $\rightarrow 3$ )-D-glucan from yeast cell walls. Biochemical Journal 135, 19-30.

NeČAS, O. (196I). Physical conditions as important factors for the regeneration of naked yeast protoplasts. Nature, London 192, 580-58I.

NEČAs, O. (1965). Mechanism of regeneration of yeast protoplasts. Folia Biologica (Praha) 11, 37I-377.

NEČAs, O. (1971). Cell wall synthesis in yeast protoplasts. Bacteriological Reviews 35, 149-170.

NeČAs, O. \& SvoBODA, A. (1967). Relation between the biosynthesis of the cell wall and regeneration in yeast protoplasts. In Symposium über Hefe-Protoplasten, pp. 67-71. Edited by R. Müller. Berlin: AkademieVerlag.

Novaes-Ledieu, M. \& Garcia-MendozA, C. (1970). Biochemical studies on walls synthesized by Candida utilis. Journal of General Microbiology 6r, 335-342.

Roelofsen, P. A. \& Hoette, I. (I95I). Chitin in the cell wall of yeasts. Antonie van Leeuwenhoek 17, $27-43$.

Ruiz-Herrera, J. \& Bartnicki-Garcia, S. (1974). Synthesis of cell wall microfibrils in vitro by a 'soluble' chitin synthetase from Mucor rouxii. Science, New York 186, 357-359.

STREIBLOVÁ, E. (1968). Surface structure of yeast protoplasts. Journal of Bacteriology 95, 700-707.

SVOBODA, A. \& NEČAS, O. (1970). Experimental decoupling in the synthesis of fibrillar and amorphous components during regeneration of the cell wall in Saccharomyces cerevisiae protoplasts. In Yeast Protoplasts. Proceedings of the Second International Symposium on Yeast Protoplasts, pp. 21 I-2 I5. Edited by $O$. Nečas and A. Svoboda. Brno: J. E. Purkyně University Press.

Wang, M. C. \& Bartnicki-Garcia, S. (1966). Biosynthesis of $\beta$-(I $\rightarrow 3$ ) and $\beta$-(I $\rightarrow 6)$-linked glucan by Phytophtora cinnamomi hyphal walls. Biochemical and Biophysical Research Communications 24, 832-838. 